\title{
Practical Steps for the Utilization of Action Research in Your Organization:
}

\section{A qualitative approach for non-academic research.}

\author{
Paul James Antonellis, Jr. (Corresponding Author) \\ Faculty \& Director of Human Resource Management Programs \\ Merrimack College, North Andover, MA \\ United States \\ Email: antonellisp@merrimack.edu \\ Gwendolyn Berry \\ Faculty \& Director Intentional Connections \\ San Jacinto Community College \\ San Jacinto College, TX.
}

\begin{abstract}
Action research is different from traditional research. Action research is more practice based as it is implementing an intervention to improve a problem. Action research involves collaboration and communication between the researcher and the participants within the study. The purpose of this article is to explain the multi-step process for a non-academic researcher or novice researcher when employing qualitative action research in an organization that is looking to solve a complex issue. The article will explore the action research steps for conducting phone employment interviews within the organization and an example of the process to follow. The outlined steps can be adjusted to any organization looking to create sustainable improvements for any problem the organization is looking to change.
\end{abstract}

Keywords: Action research, qualitative, discovery, change, qualitative 


\section{Introduction}

Action Research has become a credible and reliable research process in the field of academia. Action Research is no longer limited to the field of academic research; today public, private, and nonprofit organizations use Action Research to take corrective action(s) in an effort to create sustainable improvements (Bradbury, 2015; James, Slater \& Bucknam, 2012). Action Research, in the simplest terms, involves the researcher building a collaboration with those involved called stakeholders, defining the problem, collecting needed data, analyzing the data, determining the needed action, implementing the action, collecting additional data while using different research methods, and finally implementing the final results to determine if the action was successful (Bell, 2014; Coghlan \& Brannick, 2014; James, Slater, \& Bucknam, 2011). If the intended results were not achieved, the Action Research process allows for the process to start over with the new information gained from the first round of research. Action Research allows the researcher to be directly involved in the research process compared to traditional academic research when the researcher is the observer and not able to make adjustments as the research process is progressing. Action Research involves having questions about a given problem that the organization is facing that the researcher would like to solve while utilizing those stakeholders who are directly involved with the problem (Coghlan \& Brannick, 2014). Action Research can be a complex and in depth process, often requiring a graduate level study course to conduct academic research. The following pages have been broken down into easy to follow steps the novice researcher or change agent could utilize for the Action Research project to create sustainable long-term improvements (James, Slater, \& Bucknam, 2011; Schultz, Mietzner \& Hartmann, 2016). The intent of this article is to expand the knowledge directly to managers and leaders in an organization on the multi-step process of conducting qualitative Action Research and how it can be utilized by the organization to bring about positive long term change.

In the following pages, we will explore what Action Research is and how it has been used in the past to provide solutions for problems, ethical considerations for conducting Action Research, assumptions and limitations that the research determines about the research project, scope of work and the literature review for the employment phone screening procedure. The outlined steps can easily be modified to the researchers' own organization when faced with a problem and looking for improvements. The paper further identifies the action to be taken in the research project, data collection and the evaluation of outcomes. The final section of this paper reviews the elements of preparing the final written report on the Action Research project.

We have selected the employment phone interview method as the qualitative research procedure as a means for providing the reader with the easy to follow progression of adopting the practice for one's own organizational problem. As discussed later, Action Research can use qualitative, quantitative, and mix-methods data collection; however, for the scope of this paper, we have selected the qualitative research method. The qualitative research method for collecting data involves in-depth interviews with research participants who have a direct or indirect interest in the complex issue. 


\section{MInstitute Macrothink $_{\text {Int }}$}

\section{What is Action Research}

There are many definitions of Action Research; for the purpose of this article, we have identified Action Research as a multiple stage process to manage positive long term change while gaining support from various stakeholders that will lead to favorable results. Action research allows for the investigator to be internal to the organization and to play an active role in the research process, and gain a deeper understanding of the issues facing the organization while gathering research participants input regarding possible solutions for the problem. The Action Research process involves not only diagnosing the issue facing the organization, but also developing and the selecting of alternative actions; key to the action research process is evaluating the outcomes of the change as shown in the Action Research Process (Figure 1) (Antonellis, \& Flam, 2016; Bradbury, 2015; Schultz, Mietzner \& Hartmann, 2016; Susman \& Evered, 1978). Action Research is a recognized academic research method with established empirical literature to support the Action Research practice. The intent of this article is to introduce the Action Research process to the non-academic or the novice researcher.

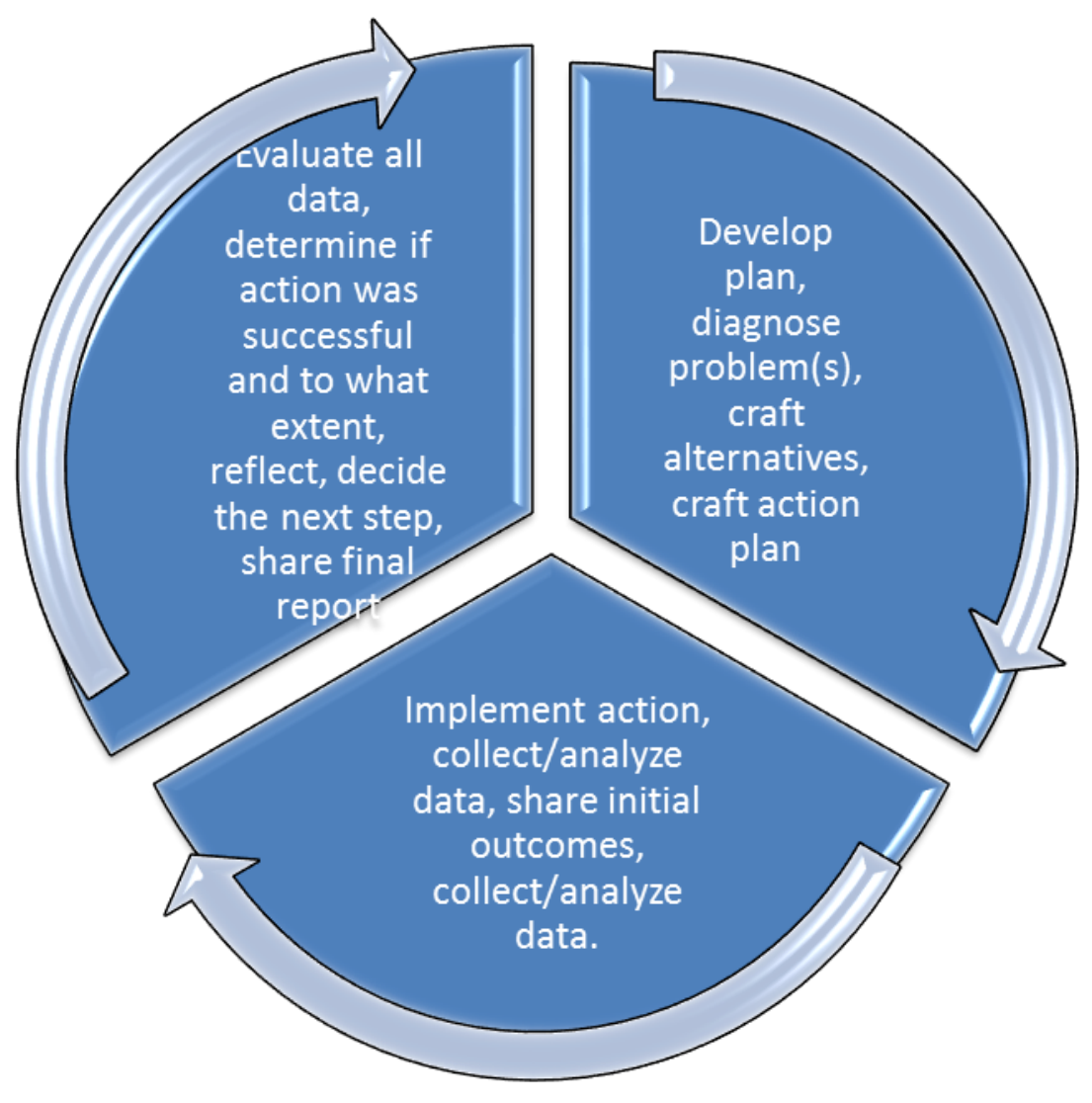

Figure 1. Action Research Process

Action research is a type of academic research with roots reaching back more than 60 years (Lewin, 1946). Action research can be used in the academic research setting or it can be used in any organization that is faced with identifying a problem, seeking input from internal and 
external stakeholders who will be impacted by the proposed change, defining the implementation, and determining the evaluation method to decide if the original outcomes have been reached (Argyris, 1992; James, Slater \& Bucknam, 2012; Sein, Henfridsson, Purao, Rossi \& Lindgren, 2011). James, Slater, and Bucknam (2012), along with Herr and Anderson (2005) asserted that the focus of the action research process in the change process involves identifying individuals who will be impacted by the problem and those who might be impacted by the problem in an effort to seek direct input on identifying a problem, seeking viable alternatives, implementing the action, measuring results, and making adjustments along the process as needed to obtain sustainable improvements.

Action research allows for the use of an internal researcher, meaning that the action research is conducted by an employee of the organization (Baskerville \& Wood-Harper, 2016; Hien, 2016; James, Slater \& Bucknam, 2012). The internal researcher has prior knowledge of the organization while the research participants have knowledge of who the researcher is, allowing for a partnership to develop compared to having an external researcher and search participants who may resist openly talking to an external researcher. The creation of respect, trust, and transparency is key to allowing stakeholders to discuss possible options and alternatives to the problem faced by the organization (Argyris \& Schön, 1989; Dick, Stringer \& Huxham, 2009; Luckett, Ngubane, \& Memela, 2001).

Organizational learning theory is used as part of the action research process. Argrys and Schön (1989) suggested that organizational learning is based in part on two modes of operation. They argue that there is a theory as to what people say and a theory as to how they act. Argrys and Schön (1989) believed that the Espoused theory and Theory-in-use are found in organization; however, they can often be conflicting resulting in challenges in organizational learning. Argrys and Schön (1996) asserted that the Espoused theory is used to explain or justify a given array of activities with the organization, whereas theory-in-use is explained as "...the theory of action which is implicit in the performance of that pattern of activity" (p. 13). The researcher will use the Theory-in-use as the researcher observes the behaviors of the participants to determine what behaviors are being governed by formal or informal rules of the research participants. In many cases, people within a formal organization may be in conflict with the Espoused theory and the Theory-in-use, not realizing how their behaviors are shaped and formed by formal and informal structures within the organization. The researcher using the two theory approach will be able to uncover behaviors of the research participants while allowing the participants the ability to make more informed decisions and actions (Argyris \& Schön, 1974; Argyris \& Schön, 1978; Coghlan \& Brannick, 2014). Argyris and Schön (1974) argued,

When someone is asked how he would behave under certain circumstances, the answer he usually gives is his espoused theory of action for that situation. This is the theory of action to which he gives allegiance, and which, upon request, he communicates to others. However, the theory that actually governs his actions is the theory-in-use (p.7). 


\section{Mll Macrothink}

International Journal of Human Resource Studies

ISSN 2162-3058

2017, Vol. 7, No. 2

The problem identified is often complex and involves various levels of motivations, ranging from transparent motivation to hidden motivations (Casey, 2012). The key to successful action research is seeking direct input from the research participants and decoding the motivations that may be intertwined within the responses from the participants (qualitative inquiry) (Berg, 2004; McNiff \& Whitehead, 2011). Antonellis (2013) suggested that participants involved in the research will need to feel that that they have an equal and respected voice in the process; that offering their voice is done in an open environment without fear of reprisal. Once the original data has been collected, the results should be shared with all of the research participants in an effort to provide transparency in the process; the participants will be able to see that the suggestions they made and are shown in the initial report (Reitz, 2016). Coghlan and Brannick (2014) suggested that it is critical to protect the identity of the research participants when releasing the initial data provided during the first set of interviews. Any personal identifying indicators should be removed from the report in an effort to protect the identity of the participants. The protection of participants' identity will further support the concept for the open, honest, and respectful communication and at the same time the participants will be able to see phrases or sentences that they may have provided which will create a sense of ownership in the change process.

\subsection{Ethical Principles \& Standards}

Action research, whether conducted in an academic or organizational setting, is bound by ethical codes and standards (For additional information on ethics: American Physiological Association, Society for Business Ethics or International Business Ethics Institute, National Council of Nonprofits). The researcher should do no harm to the participants of the research project from a physical or emotional standpoint. Internal researchers need to ensure that research participant's rights and dignity are protected during the process and the reporting of the final results (Denzin \& Lincoln, 2017; Salmons, 2015; Stuckey, 2014). Herr and Anderson (2005) insisted that before starting an action research project, the researcher should seek the advice of senior administration on ethical codes that the company follows for the research and the protection of research participants. The use of informed consent forms outlining the research, the known risk to participants, how data will be collected from participants, how the data will be analyzed, and how participants can withdraw from the research project at any point, and contact information for the internal researcher are essential in the research process. Demchenko, De Laat and Membrey (2014) insisted that the researcher must ensure that the research raw data and the names of participants will be stored in a locked cabinet and that no one will have access to this information. This includes the audio recordings of the interviews, and timeframes as to when the interviews electronic copies will be erased. The researcher should consider how long the raw data will be stored and how it will be destroyed while protecting the identity of the participants (Coghlan \& Brannick, 2014; Heffetz \& Ligett, 2014). As the researcher, reach out to a local college or university for additional information on ethical standards pertaining to research and to obtain a draft copy of an informed consent form for conducting research. 


\subsection{Assumptions}

Academic research requires that the researcher identify and explain the limitations and the assumptions for the research project. A clear assumption statement prevents any misunderstandings of the material bearing on the problem. Assumptions are considered items that are out of the control of the researcher (Ormston, Spencer, Barnard, \& Snape, 2014; Trafimow, 2014). For example, in our sample of qualitative employment interview research: 1) We assume that the participants will provide truthful responses; 2) We assume that the qualitative questions asked provide responses for the group we are making inferences to; 3 ) We assume that if the organization uses our suggestions in the final written research report that the organization will be successful based on our research, education, and experience.

Each researcher will bring a certain level of bias to a research project and to reduce this bias is to self-reflect on any possible biases, identify and list possible steps to minimize the bias in the project (Bryman \& Bell, 2015; Coghlan \& Brannick, 2014; Denzin \& Lincoln, 2017). In academic research, the standard of practice to limit assumptions is to have a colleague review the data to see if the results are based on the data and not the researchers' bias (Ebrahim, 2016; Gravetter \& Forzano, 2015). As an internal organizational researcher, consider contacting a colleague who has prior experience with data analysis or contact a local college/university to see if a student is available to review the data collected. Denzin and Lincoln (2017) suggested that having a second reviewer of data will add credibility to the researchers' research project and minimize possible areas of bias and assumptions in the reporting.

\subsection{Limitations}

Limitations identified are areas that the research project contained. Some of the limitations might be identified as pre-project, project, and post-project. The final written report will contain the research project limitations (Barbour, 2001; Denzin \& Lincoln, 2017). In an effort to show what research limitations may look like, the following are limitations we identified in our employment research project:

- The research project final written report was due within 120 days; we suggest additional time if this research is reproduced;

- The research was conducted in one organization and that the findings cannot be expected to apply to all organization and we suggest multiple organization be included in future research;

- The research was limited to eighteen participants in the qualitative research sample, we recommend increasing the sample size in an effort for deeper exploration of the topic;

\subsection{Action Research in Your Organization}

The first phase of the Action Research process, draft the scope of the research which will define the research plan. The scope will outline the stakeholders (population size) who may be involved in the research project. The scope will need to define the time limitations for the research, and projecting accurate time for results will help those involved in the research as a 
guide for participation (McNiff \& Whitehead, 2011). If this is the first attempt at using action research, it would be best to provide extra time for any challenges the researcher did not anticipate in the original plan that may prolong the process. Coughlan and Coghlan (2002) suggested that the scope of the research is a critical aspect of developing the research plan, which is the roadmap for the research project.

\section{Scope of Research}

During the development of the scope of the research, the researcher will develop the background and the context to the problem the organization is currently facing; this is the beginning stage of the research planning process. Coughlan and Coghlan (2002) suggested that the information gathered and used to help define the problem will aid in the creation of the action research final report so others will understand the background of the issue, the content of the issue, and theoretical content to the problem faced by the organization. The researcher will want to explain how the problem arose, how others view and think of the problem, and to determine if participants have any suggestions at this informal stage (Checkland \& Holwell, 1998; Ozanne \& Saatcioglu, 2008; Watkins, Nicolaides, Marsick, 2016). The "preliminary data" collected at this informal stage will help clarify the issue (diagnose the problem) and develop alternatives to ensure that the research project is necessary and that the correct issue is being studied (Figure 1). A word of caution at this stage: the researcher should not immerse themselves too deep in the literature review, as doing so could create bias when the researcher begins conducting interviews with participants.

\section{Literature Review}

After completing the scope of research, the second phase would be to begin the literature review process. The literature review ensures that the researcher has a comprehensive understanding of the issue facing the organization. The literature identified will help form the action research plan (Figure 1). The literature review will include researching and identifying key concepts, key debates, theoretical perspectives, and any historical perspectives surrounding the problem the organization is facing (Alber, 2011; Ebrahim, 2016). Webster and Watson (2002) emphasized that the literature review will consist of locating articles, books, interviews, and case studies. The literature review is more than just conducting an online web search such as "Googling something" or finding a blog posting. The goal is to research and identify some academic research on the topic under review (Bryman \& Bell, 2015). Access to academic research portals can often be obtained at a local library. Many libraries now have online search engines for its customers; once the new customer registers with the library as a user, this will allow the customer full access to conducting searches online remotely. Another source would be to use a local college or university library to conduct a literature search.

The literature review may include current documents pertaining to the problem that the organization is facing. The documents may be internal documents, records, reports, meeting minutes, and other artifacts that will help in describing the problem, historical aspects, and the behavior surrounding the issue (Coghlan \& Brannick, 2014; Stringer, 2007). As the research project advances, additional literature may be needed as themes are developed. At 
this point, the researcher is ready to identify the methodology of the proposed research project.

Keeping a detailed listing of the literature reviewed will be beneficial as the researcher prepares to write the final report, making it easy to locate and cite the content (Bryman \& Bell, 2015). The researcher may want to use a free software to keep track of the literature such as Mendeley or set up a simple spreadsheet for easy retrieval. Once the researcher completes the literature review, it will be easy to group the common themes in an effort to organize the review. The grouping may be key concepts, key debates, theoretical perspectives or historical perspectives as a starting point (Wolfswinkel, Furtmueller \& Wilderom, 2013). The researcher will review each article in an attempt to identify how useful the article is to the research project, while making note of the following sections:

- Author(s)

- Date

- Article Title/Document Title

- Volume/Issue

- Source/Publisher

- Key Points

\section{Qualitative Research}

The third phase of the action research is identifying the methodology which identifies the implementation plan (Figure 1). The third phase will show how the researcher will conduct the research. The researcher at this phase should decide what the best procedure is and which activities will answer the research questions for the project. The researcher may decide on qualitative, quantitative, or mix method (Creswell, 2003). For the purpose of this article, we are using qualitative inquiry to seek discovery and understanding, and collect and analyze data, in an effort to use participants' words to ensure that ideas are accurately reflected (McNiff \& Whitehead, 2011). There are various traditional qualitative inquiries used; the most common in business organizations is the generic qualitative inquiry which is used in an effort to record opinions, attitudes, beliefs, or experiences in order to seek discovery and understanding (Caelli, Ray \& Mill, 2003; Doz, 2011, Erickson, 2011 Granot, Brashear \& Cesar Motta, 2012). The selection of the method will play a role in the timeframe for collecting, analyzing, and reporting of the data.

The researcher conducting qualitative inquiry for the action research project serves as the research instrument (Ormston, Spencer, Barnard \& Snape, 2014; Patton, 2005). The researcher may collect data from the following sources: field notes, observations, interviewing, focus groups, journaling, historical documents, photos, video, films, drawings, online sources (Coghlan \& Brannick, 2014; Patton, 2002; Salmons, 2015). Qualitative inquiry allows for smaller sampling sizes; for example, 10-20 participants would be 
considered an approved sampling (Creswell, 2003). The goal is to seek meaning from the spoken words of each participant in order to obtain meaning beyond appearance and obvious words (Bryman \& Bell, 2015; Crouch \& McKenzie, 2006 Gravetter \& Forzano, 2015). During the initial data analysis, thematic coding can be utilized in order to identify emerging themes from the initial interview transcriptions. The use of thematic coding can be conducted by the researcher and would not require a comprehensive qualitative data software program (Ormston, Spencer, Barnard, \& Snape, 2014). If the projected research will involve a larger sampling greater than 25 participants, the researcher may want to consider computer software to help organize and analyze data.

Once the initial data has been analyzed, it is best to share the results with all of the research participants in an effort to be transparent. In addition, this step allows an opportunity to self-reflect on the initial results. The first data collection provides a measurement as to the starting point of the action research and it is often considered an exploratory process. Based on the original interview data, the researcher will gain a deeper understanding of the issue and viable alternatives for a solution (Coghlan \& Brannick, 2014; Sekaran, 2006). The review and reflection of the initial data may also reveal additional information that will allow for the modification of the actions. At this stage, the researcher has an opportunity to adjust the research and align the research with a positive long term outcome to the problem faced (James, Slater, \& Bucknam, 2011; McAnaney \& Williams, 2010). The sharing of initial data will assist in building and maintaining a sense of community with the research participants and at the same time keep the research purpose clearly in mind with each of the participants.

\section{The Action}

Once the original data has been analyzed and the researcher is ready to release the initial results to the participants, the researcher may choose to maintain a daily handwritten reflection $\log$ to record what the researcher did and what results were observed. The reflection log now becomes part of the data that can be later analyzed as part of the action research project. The reflection log allows the researcher to record ideas, thoughts and observations as the research project progresses. While keeping the final research report in mind, the researcher is able to make connections and links to the literature as the initial interviews are conducted (Stringer, 2014; Stuckey, 2014). The researcher may want to start by repeatedly asking herself/himself:

- "How do the things I have read about in the literature compare/contrast to what I am seeing about the problem I am investigating?

- "What are some of the assumptions that the participants hold and why?"

- "What are the norms and traditions within the organization?"

- "Are the participants speaking freely and what is the level of the defensiveness?"

The researcher that identifies literature that is linked the theory or influencing the content should be recorded with the proper citation and references for easy retrieval at a later time 
when preparing the final report (Argyris, 2002; Coghlan \& Brannick, 2014, Stringer, 2014). The reflection log should be updated on a weekly basis, so plan on leaving time each week for this important action. The log allows the researcher to document the steps taken during the research project, what the researcher discovered, and what action, if any, the researcher took.

Coghlan and Brannick (2014) suggested that the next phase in the research project would be to analyze the initial data sets and determine what action the researcher will be taking and what will be measured. Continuing with our qualitative data collection we identified above, common themes were identified from the data and codes were used to specify ideas from the literature (Bell, 2014; Ormston, Spencer, Barnard \& Snape, 2014). For our example; based on the initial interviews, the data suggested that people are missing a clear direction of the hiring process at the company and that the current hiring is conducted differently by each department in the organization. The data revealed that the participants suggested a written policy on the hiring procedure was needed and to conduct a brief hiring training for any member involved in the hiring procedure for the company. The participants reported types of interview questions they might use and what they are trying to obtain from the answer provided (Antonellis \& Flam, 2016). In this case, the researcher would now work on developing a written policy based on the suggestion offered during the initial interviews, the current literature, and the artifacts provided by the company pertaining to the area being researched. The researcher would develop a professional development session based on the data, current literature, and organizational artifacts in an effort to bring about change in the organization going forward (Bell, 2014; Hind, Smit, \& Page, 2013; Stringer, 2014).

It will be during the professional development session that the researcher will have an option to collect data based on the researcher observations of the participants during the session (Kragelund, Moser \& van Zadelhoff, 2015). It will be during the professional development session that the initial data is released and presented how it was incorporated into the written guidelines and the training session (Figure 1). The participants at this point will have another opportunity to discuss in an open forum the ideas and content in the written guidelines, allowing for the participants to see that they did have a voice in the process and this may result in further support (Caruth, \& Caruth, 2013; Morsing, \& Schultz, 2006). The professional development allows the researcher to refine any miscommunications or to further identify any new resistance points with the project, while training the participants on the steps for conducting a proper employee interview (Camp, Schulz, Vielhaber \& Wagner-March, 2011). When the researcher utilizes journals, meeting notes, and observation data from a qualitative standpoint, it offers purposeful value and quality checks (James, Slater \& Bucknam, 2012). Stringer (2014) suggested, "The heart of action research is not the techniques and procedures that guide the action but the sense of unity that holds people to a collective vision of their world and inspires them to work together for the common good" ( $p$. 132). The data collected at this point will be analyzed and adjustments made to the research if needed. Denzin and Lincoln (2017) added it is not uncommon for action research projects to be adjusted during the research process.

At this point, the professional development session has been conducted and the data collected 
during the session analyzed and incorporated into the research project. To recap, we now have an initial interview process as a data point (baseline data), the literature review as a second data point, and the professional development training session observation protocol as another data point for the research project. The final data collection point for the project will be the post-professional development session interviews with participants.

\section{Final Data Collection}

The original data and the professional development session has been conducted, and the next step is to conduct the final interviews with the research participants. The research participants need to commit to participating in all three sections: original interviews (baseline), professional development session, and the post-professional development session interviews. The final interview questions would focus on the changes that have been suggested and the results. In the interview scenario discussed above, our goal would be to seek input from participants on what new insight they have gained by the proposed written guidelines in the professional development session (Stringer, 2014; Townsend, 2013). The researcher could also seek additional input on areas of the training that still need improvement or additional suggestions that have surfaced during or after the professional development session.

As the researcher, leave ample time to conduct the final set of interviews, transcribe, analyze, and report the findings in a final report to the organization (Reitz, 2016; Stuckey, 2014). With action research, the aim is to focus on the common themes from the data and try to uncover hidden motives of individuals who look to negatively impact the research. This could be traced by money, culture, history, ego, position in the organization, or power. Action research is based upon the idea that the process is democratic and that all participants have an open, honest, and respectful input in the process (Gaventa \& Cornwall, 2008; Townsend, 2013). The final data collection will provide evidence as to any changes in behavior and/or beliefs of the participants after the professional development intervention and compare it to the pre-intervention interview data from the research participants.

The data collected from the research participants will serve as one source of data collection; the data collected from the literature review will serve as a second data point; and the observation protocol during the professional development session will serve as a third data point (Erzerberger \& Prein, 1997; Hussein, 2015; Strang, 2015). The three data points create a triangulation of data in an effort to increase the accuracy of the data be represented resulting in validity of the data (Abro, Khurshid \& Aamir, 2015; Hussein, 2015). Creswell and Miller (2000) observed triangulation as "a validity procedure where researchers look for convergence among multiple and different sources of information to form themes or categories in a study" (p. 126). Allowing for three-point data collection will provide the best approach to capturing the "voice" of the participants in the research.

\subsection{Evaluating Outcomes}

After the final data collecting process, the data is ready for interpreting and analyzing (Figure 1). The analysis should reveal whether or not the results brought a solution or support to the problem. Rereading or reviewing the Scope of Research section may be helpful when 
evaluating the research outcomes. Stringer (2014) suggested that further evaluation should confirm if and how the results from the action research study may confirm the researchers' assumptions, which pertains to the framework of the study.

The next step in the analyzing process is to interpret how the data results related to the literature review section. Gay, Mills and Airasian (2006) declared displaying a connection between the research project results and the work of other researchers ensures credibility and relevance of the action research study. Determine the extent of the research outcome meaning; "Did the data display a connection between the results and the literature of review?" Bradbury (2015) claimed that the goal of action research is to determine why there was a connection or why there was not a connection with the research findings to the problem(s) and how they all interconnect to the current literature. This information could be useful if the researcher or others within the organization decides to conduct additional research on the topic (Coghlan \& Brannick, 2014). Part of any research project is that the research will identify key elements of the research conducted to allow future researchers to replicate the research and possibly the findings. The research project will attempt to fill a gap in the literature or including an identified limitation in the researcher research.

Another factor to evaluating outcomes is assessing strengths and weaknesses of the data collected for the research project. Did the researcher have sufficient evidence to support the action research study? Not having adequate supporting data is a weakness (mistake) that is typically made by novice action researchers (Booth, Colomb \& Williams, 2008; Watkins, Nicolaides \& Marsick, 2016). Effectively evaluating the outcomes will benefit the final report results for it represents dependability, which means that the data outcomes are reliable and accurate (Turner, 2010; Ormston, Spencer, Barnard \& Snape, 2014; Susman \& Evered, 1978). Evaluation of data outcomes is a critical step in the action research process and will determine how reliable and credible the research findings are in the researchers' final report.

A common problem with implementing a change in any organization is the "change," which is a central issue to the Action Research process; it involves selecting the best solution for the complex issue, implementing the change, and then failing to evaluate the results (Argyris, \& Schön, 1996; Caruth \& Caruth, 2013; Stringer, 2014). The evaluation of the results is one area that is often overlooked with negative results. The researcher should be asking themselves:

- "Did we make progress towards solving the complex issue?

- "What new questions have come to light as a direct result of the findings?

- "How does the data results align with the current body of literature?"

One aspect of Action Research to be considered is to determine if the evaluation of the results failed to solve the complex issue, and whether or not the researcher has the ability to adjust the research. The researcher can start the process again now that new information has come available and that the researcher knows the results did not solve the problem; this step may further define the problem (James, Slater \& Bucknam, 2011; Sekaran, 2006; Stringer, 2014). 
Some may view not solving the problem as a failure, but in Action Research it is acceptable to readjust the research during the process. Not achieving the intended results may be the result of a number of issues from search design to substandard data collection, regardless, now is the time to regroup and determine the best action (Bradbury, 2015; Stringer, 2014). It could be that the researcher has not properly identified the root cause of the issue at the original planning stage of the research and the original investigation only scratched the surface but by going back, the researcher will be able to extract a deeper meaning to the solution.

\section{Report Results}

Denzin and Lincoln (2017) suggested that the manner in which the researcher reports on the research results in a written format will lend itself to creating a level of credibility for the research project and the researcher. When another person reads the final research report, will they think to themselves that the content makes sense and is convincing? If people read the report and end up questioning the process or the method of the research, the report loses credibility and the principal researcher will lose credibility as a researcher. Losing credibility as a researcher may have a negative impact on future research projects the researcher is involved in (Bradbury, 2015; Coghlan \& Brannick, 2014). Reitz (2016) and Stringer (2014) contended that the written report results illustrate how the action research project could be relevant within the host organization (research location) and how it may relate to outside organizations facing the same complex issues.

Denzin and Lincoln (2017) acknowledged that the final report should be written in a format that is consistent with the intended audience. For example, will the report be published in an academic science research journal, trade journal, or used only within the organization. The language and tone used in the report should be consistent with the intended audience; non-profit organization, public sector, academic. The final report should reveal recommendations for future researchers who may face the same complex issue identified in the research or recommendations on how to expand the knowledge base on this complex issue on future research. Recommendations could possibly suggest that further research is recommended or that the action research be regularly employed within the organization (Coghlan \& Brannick, 2014; Stringer, 2014). During the original literature review process, as the researcher is looking at prior research on the complex issue, the researcher is attempting to gain insight to the limitations and recommendations that prior researchers have listed in their report. The recommendations and limitations may help guide the researcher in developing the action research project.

\section{Conclusion}

The Action Research process is a multi-step process that can be utilized in public, private, and non-profit organizations looking to solve complex issues faced by the organization. Action research allows the researcher to tie the actions taken in the research and link them to methodology while using a process of reflection to provide a solid foundational base for the research project (Coghlan \& Brannick, 2014; Townsend, 2013). This article has highlighted some of the key areas that a nonacademic researcher may want to include in the development 
of an action research plan for an organization. The Action Research process is not intended to solve every situation issue; Action Research, like any other tool, has limitations. Selecting the proper research tool for solving the organizational complex issues is the starting point. Action Research can use qualitative, quantitative, or a mix of the two for collecting data; as discussed, we chose to focus on qualitative research for our example for this article (Creswell, 2003).

Collaboration is a central issue in the Action Research process, with internal and external stakeholders who may be impacted directly or indirectly by the complex issue facing the organization. The collaboration process is an ongoing process during the research and will be time consuming for the internal researcher. Equally important is providing a level of balance for the researcher's time and the time commitment for the participants in the project. To that end, the research project planning stage should include an ample time commitment to the collaboration process to yield the best results for the project (Bradbury, 2015). A novice researcher may underestimate the time commitment to the collaboration process and the time for conducting and analyzing the data.

As with any research or professional action, ethical considerations must be given and Action Research is no different. As an internal researcher, take steps to not allow the researchers personal bias to taint the research. Collaborating with others about the research project will aid in this process. Being honest with the research projects limitations and recommendations will further build credibility for the research project and the researchers' professional reputation as a researcher. As discussed, conducting an initial literature review early in the process will provide a foundation to build on as the researcher develops the scope of work statement. As the project progresses, a more comprehensive literature review will help the researcher better understand the issues surrounding the complex issue and to gain a deeper understanding of the issues.

We have discussed the process of data collection and the evaluating of outcomes for the research project. The evaluation is not just limited to the data collected from participants, the evaluation process determines how the data results relate to the literature review. Essentially, the researcher will want to determine if the results are the same as other research findings or are the results different. The results will be reported in the final written report. The final step in this multi-step process will involve writing the final report. The final written report will be disseminated to all research participants and those that are directly impacted by the complex issue. The written report will help others to understand how the solution was crafted, what the current literature has to say about the topic, how the solution was implemented, and the final evaluation of the results after the solution was implemented to show that it was successful. The written report will also provide an avenue for future researchers to build on and attempt to address some of the limitations or recommendations identified in this project.

After reading this article, we encourage you to think about how Action Research could help your organization. We also encourage the researcher to review the reference list for this article on additional literature that the researcher may want to review before starting an Action Research project. The intent of this article was not to make the reader an expert in the 


\section{Macrothink}

International Journal of Human Resource Studies

ISSN 2162-3058

2017, Vol. 7, No. 2

field of Action Research; rather, the intent was to explain the multi-step process when employing qualitative action research in an organization that is looking to solve a complex issue. Our hope is that this article has extended the readers interest in the area of Action Research. Action Research can make a profound positive long-term impact on the organization, so do not simply read this article and set it aside; take action and see the results that Action Research can bring to the organization. Be sure to reflect on each process during the Action Research journey and once you have completed the first research project, take the time to reflect on what could be done different the next time and what were some of the positive outcomes you found helpful this time.

\section{References}

Abro, M. M. Q., Khurshid, M. A., \& Aamir, A. (2015). The use of mixed methods in management research. Journal of Applied Finance and Banking, 5(2), 103.

Alber, S., (2011). A toolkit for action research. New York, NY: Rowman \& Littlefield

Antonellis, P. (2013). Revisiting action research. Journal of Social Science, Vol. 1, No. 1, p 12-20.

Antonellis, P., \& Flam, D., (2016). Phoning it in? Examining pre-employment phone interview procedure in higher education. International Journal of Human Resource Studies, 6(1), 21-45.

Argyris, C. (1992). On organizational learning. Malden, MA: Blackwell

Argyris, C., (2002). Double-loop learning, teaching and research. Academy of Management Learning and Education, 1(2).

Argyris, C., \& Schon, D. (1974) Theory in practice: Increasing professional effectiveness. San Francisco: Jossey Bass.

Argyris, C., \& Schon, D. (1978) Organizational learning: A theory of action perspective. Reading, Mass: Addison Wesley.

Argyris, C., \& Schön, D. A. (1989). Participatory action research and action science compared. American Behavioral Scientist, 32, 612-623. http://dx.doi.org/10.1177/ 0002764289032005008

Argyris, C., \& Schön, D. (1996). Organizational learning II: Theory, method and practice. Reading, PA: Addison-Wesley.

Barbour, R. S. (2001). Checklists for improving rigour in qualitative research: a case of the tail wagging the dog?. BMJ: British Medical Journal, 322(7294), 1115.

Baskerville, R. L., \& Wood-Harper, A. T. (2016). A critical perspective on action research as a method for information systems research. In Enacting Research Methods in Information Systems: Volume 2 (pp. 169-190). Springer International Publishing.

Bell, J. (2014). Doing Your Research Project: A guide for first-time researchers. 


\section{Al Macrothink}

International Journal of Human Resource Studies

ISSN 2162-3058

2017, Vol. 7, No. 2

McGraw-Hill Education (UK).

Berg, B. L. (2004). Qualitative research methods for the social sciences (Vol. 5). Boston, MA: Pearson.

Booth, W., Colomb, M. and Williams, J.M., (2008). The Craft of Research, 197.

Bradbury, H. (Ed.). (2015). The Sage handbook of action research. Washington, DC: Sage.

Bryman, A., \& Bell, E. (2015). Business research methods. New York, NY: Oxford University Press.

Caelli, K., Ray, L., \& Mill. J. (2003). 'Clear as mud': Toward greater clarity in generic qualitative research. International Journal of Qualitative Methods, 2(2).

Camp, R., Schulz, E., Vielhaber, M., \& Wagner-March, F. (2011). Human resource professionals' perceptions of interviewer training. Journal of Managerial Issues. 33(3). P 250-268.

Caruth, G., \& Caruth, D. (2013). Understanding resistance to change: A challenge for universities. Turkish Online Journal of Distance Education. 12(2). P 12-21.

Casey, A., (2012). A self-study using action research: Changing site expectations and practice stereotypes. Educational Action Research. Vol. 20, No. 2. p. 219-232

Checkland, P., \& Holwell, S. (1998). Action research: its nature and validity. Systemic Practice and Action Research, 11(1), 9-21.

Coghlan, D., \& Brannick, T. (2014). Doing action research in your own organization (4 ${ }^{\text {rd }}$ ed.). Washington, DC: Sage.

Coughlan, P., \& Coghlan, D. (2002). Action research for operations management. International journal of operations \& production management, 22(2), 220-240.

Creswell, J. W. (2003). Research design: Qualitative, quantitative, and mixed methods approaches $\left(4^{\text {th }}\right.$ ed.). Thousands Oaks, CA: Sage.

Creswell, J. W., \& Miller, D. L. (2000). Determining validity in qualitative inquiry Theory into Practice, 39(3), 124-131.

Crouch, M., \& McKenzie, H. (2006). The logic of small samples in interview-based qualitative research. Social science information, 45(4), 483-499.

Demchenko, Y., De Laat, C., \& Membrey, P. (2014). Defining architecture components of the Big Data Ecosystem. In Collaboration Technologies and Systems (CTS), 2014 International Conference on (pp. 104-112).

Denzin, N. K., \& Lincoln, Y. S. (2017). The Sage handbook of qualitative research, $5^{\text {th }} \mathrm{Ed}$. Sage.

Dick, B., Stringer, E., \& Huxham, C. (2009). Theory in action research. Action research, 7(1), 5-12. 


\section{Macrothink}

International Journal of Human Resource Studies

ISSN 2162-3058

2017, Vol. 7, No. 2

Doz, Y. (2011). Qualitative research for international business. Journal of International Business Studies, 42(5), 582-590.

Ebrahim, N. A. (2016). Research Tools: Scientific Writing Tools for Writing Literature Review and a Paper. DOI: 10.6084/m9.figshare.2082625

Erickson, F. (2011). A history of qualitative inquiry in social and educational research. The Sage handbook of qualitative research, 4, 43-59.

Erzerberger, C., \& Prein, G. (1997). Triangulation: Validity and empirically based hypothesis construction. Quality and Quantity, 31, 141-154.

Gaventa, J., \& Cornwall, A. (2008). Power and knowledge. In P. Reason \& H. Bradbury (Eds.), The SAGE handbook of action research: Participative inquiry and practice $\left(2^{\text {nd }} e d\right)$. London: Sage

Gay, L. R., Mills, G. E., \& Airasian, P; (2006). Educational Research: Competencies for Analysis and Applications ( $8^{\text {th }}$ ed). Columbus, $\mathrm{OH}$ : Pearson.

Granot, E., Brashear, T. G., \& Cesar Motta, P. (2012). A structural guide to in-depth interviewing in business and industrial marketing research. Journal of Business \& Industrial Marketing, 27(7), 547-553.

Gravetter, F., \& Forzano, L. A. (2015). Research methods for the behavioral sciences. Stamford, CT: Cengage.

Heffetz, O., \& Ligett, K. (2014). Privacy and data-based research. The Journal of Economic Perspectives, 28(2), 75-98.

Herr, K. and Anderson, G. (2005). The action research dissertation: A guide for students and faculty. Thousand Oaks, CA: Sage

Hien, T. T. (2016). Why is action research suitable for education? VNU Journal of Science: Foreign Studies, 25(2).

Hind, P., Smit, A., \& Page, N. (2013). Enabling Sustainability through an Action Research Process of Organizational Development. Journal of Corporate Citizenship, (49), 137-161.

Hussein, A. (2015). The use of triangulation in social sciences research: Can qualitative and quantitative methods be combined? Journal of Comparative Social Work, 4(1).

James, E. A., Slater, T., \& Bucknam, A. (2011). Action research for business, nonprofit, and public administration: A tool for complex times. Washington, DC: Sage.

Kragelund, L., Moser, A., \& van Zadelhoff, E. (2015). Using the Obser-View in Qualitative Research: Benefits and Challenges. International Journal Of Qualitative Methods, 14(5), 1-9. doi:10.1177/1609406915621426

Lewin, K. (1946). Action research and minority problems. Journal of Social Issues, Vol. 2 No. 4, p 34-46. 


\section{Macrothink}

International Journal of Human Resource Studies

ISSN 2162-3058

2017, Vol. 7, No. 2

Luckett, S., Ngubane, S., \& Memela, B. (2001). Designing a management system for a rural community development organization using a systemic action research process. Systemic Practice and Action Research, 14(4), 517-542.

McAnaney, D., \& Williams, B. (2010). Internalizing disability management: Using action research to explore organizational change processes. International Journal of Disability Management, 5(2), 32-39. doi:10.1375/jdmr.5.2.32

McNiff, J., \& Whitehead, J. (2011). All you need to know about action research. London: Sage Publications.

Morsing, M., \& Schultz, M. (2006). Corporate social responsibility communication: stakeholder information, response and involvement strategies. Business Ethics: A European Review, 15(4), 323-338. doi:10.1111/j.1467-8608.2006.00460.x

Ormston, R., Spencer, L., Barnard, M., \& Snape, D. (2014). The foundations of qualitative research. Qualitative research practice. A guide for social science students and researchers, $1-25$.

Ozanne, J. L., \& Saatcioglu, B. (2008). Participatory Action Research. Journal Of Consumer Research, 35(3), 423-439.

Patton, M. Q. (2005). Qualitative Research. Encyclopedia of Statistics in Behavioral Science. DOI: 10.1002/0470013192.bsa514

Patton, M. (2002). Qualitative research and evaluation methods $\left(3^{\text {rd }}\right.$ ed.). Newbury Park, CA: Sage

Reitz, M. (2016). Analyzing and communicating action research data: Practical approaches to conveying the quality and texture of experience. Action Research, 1476750316660364.

Salmons, J. E. (2015). Doing qualitative research online. Thousand Oaks, CA: Sage.

Sein, M. K., Henfridsson, O., Purao, S., Rossi, M., \& Lindgren, R. (2011). Action design research. MIS quarterly, 37-56.

Sekaran, U. (2006). Research methods for business: A skill building approach. Hoboken, NJ: John Wiley \& Sons.

Schultz, C., Mietzner, D., \& Hartmann, F. (2016). Action Research as a Viable Methodology in Entrepreneurship Research. In Complexity in Entrepreneurship, Innovation and Technology Research (pp. 267-283). Springer International Publishing.

Strang, K. D. (2015). Selecting Research techniques for a Method and Strategy. In The Palgrave Handbook of Research Design in Business and Management (pp. 63-79). Palgrave Macmillan US. DOI 10.1007/978-1-137-48495-6_5

Stringer, E., (2014). Action research (4 ${ }^{\text {th }}$ ed.). Thousands Oaks: Sage.

Stuckey, H. L. (2014). The first step in Data Analysis: Transcribing and managing qualitative research data. Journal of Social Health and Diabetes, 2(1), 6. 


\section{Al Macrothink}

International Journal of Human Resource Studies

ISSN 2162-3058 2017, Vol. 7, No. 2

Susman, G. I., and Evered, R. D. (1978). An assessment of the scientific merits of action research. Administrative Science Quarterly, 23(4), p. 582-603.

Townsend, A. (2013). Action research: The challenges of understanding and changing practices. Berkshire, England: McGraw-Hill International.

Trafimow, D. (2014). Considering quantitative and qualitative issues together. Qualitative Research in Psychology, 11(1), 15-24.

Turner III, D. W. (2010). Qualitative interview design: A practical guide for novice investigators. The qualitative report, 15(3), 754.

Watkins, K. E., Nicolaides, A., \& Marsick, V. J. (2016). Emerging Action Research Traditions: Rigor in Practice. International Journal of Adult Vocational Education and Technology, 7(3), 71-81.

Webster, J., \& Watson, R. (2002). Analyzing the Past to Prepare for the Future: Writing a Literature Review. MIS Quarterly, 26(2), Xiii-Xxiii. Retrieved from http://www.jstor.org/stable/4132319

Wolfswinkel, J. F., Furtmueller, E., \& Wilderom, C. P. (2013). Using grounded theory as a method for rigorously reviewing literature. European journal of information systems, 22(1), 45-55.

\section{Copyright Disclaimer}

Copyright for this article is retained by the author(s), with first publication rights granted to the journal.

This is an open-access article distributed under the terms and conditions of the Creative Commons Attribution license (http://creativecommons.org/licenses/by/4.0/). 